\title{
Carotid MR angiography using pulsed continuous arterial spin labeling
}

\author{
Koktzoglou loannis ${ }^{*}$, Robert R Edelman \\ From 2011 SCMR/Euro CMR Joint Scientific Sessions \\ Nice, France. 3-6 February 2011
}

\section{Introduction}

Carotid artery disease is a major cause of cerebral ischemia and infarction. It is routinely assessed using contrast-enhanced magnetic resonance angiography (MRA). Several methods for nonenhanced MRA exist, which may be particularly advantageous in patients with impaired renal function due to the risk of nephrogenic systemic fibrosis. Pulsed arterial spin-labeled (ASL) MRA has been investigated for carotid MRA, however, the signal to noise ratio (SNR) with the method is problematic when short repetition times are used to minimize scan time or when long labeling times are used to maximize visible vessel length. In contrast to pulsed ASL (PASL), we hypothesized that pulsed continuous ASL (PCASL) would provide improved SNR at short repetition times and/or long labeling durations.

\section{Purpose}

To investigate the performance of pulsed continuous ASL (PCASL) for carotid MRA, with comparison to conventional pulsed ASL (PASL).

\section{Methods}

This study was approved by our institutional review board. PCASL and PASL carotid MRA were compared in 5 volunteers (10 carotid arteries) using a $1.5 \mathrm{~T}$ scanner (Avanto, Siemens). Imaging was performed using a coronal 3D balanced steady-state free precession slab centered at the carotid bifurcations. Common imaging parameters were: field of view of $256 \times 320 \mathrm{~mm}$, spatial resolution of $1 \mathrm{x} 1 \mathrm{~mm}, 641$-mm-thick slice after interpolation, repetition times of 1.2-2.0s, acquisition times of $98 \mathrm{~s}-164 \mathrm{~s}$, labeling times of $0.9 \mathrm{~s}-1.7 \mathrm{~s}$, parallel imaging (GRAPPA) acceleration of 3. Arterial signal measurements were obtained from the PCASL and PASL

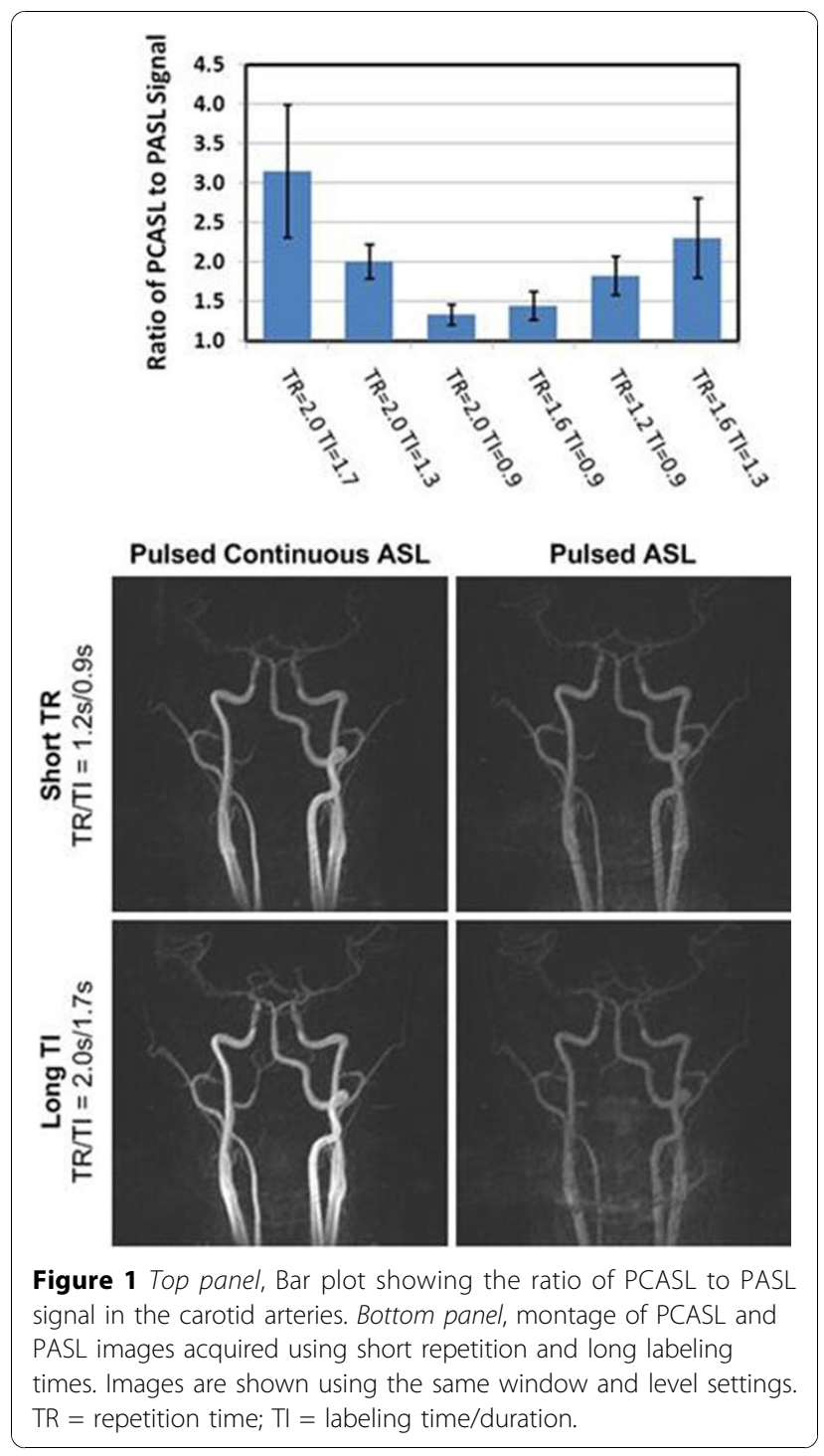

NorthShore University HealthSystem, Evanston, IL, USA 
image sets, and the ratio PCASL to PASL signal was computed.

\section{Results}

PCASL provided significantly larger arterial signal measurements than PASL for all repetition and labeling times investigated (Figure 1, top panel) $(\mathrm{P}<0.05)$. The PCASL method improved the clarity with which the carotid arteries were depicted, especially when short repetition times $(\mathrm{TR}=1.2 \mathrm{~s}$ ) and long labeling durations $(\mathrm{TI}=1.7 \mathrm{~s})$ were used (Figure 1 , bottom panel).

\section{Conclusion}

Compared with pulsed ASL, pulsed continuous ASL is advantageous for carotid MRA because it maximizes vascular signal and minimizes the adverse effects of short repetition or long labeling times.

Published: 2 February 2011

doi:10.1186/1532-429X-13-S1-P371

Cite this article as: loannis and Edelman: Carotid MR angiography using pulsed continuous arterial spin labeling. Journal of Cardiovascular

Magnetic Resonance 2011 13(Suppl 1):P371.
Submit your next manuscript to BioMed Central and take full advantage of:

- Convenient online submission

- Thorough peer review

- No space constraints or color figure charges

- Immediate publication on acceptance

- Inclusion in PubMed, CAS, Scopus and Google Scholar

- Research which is freely available for redistribution

Submit your manuscript at www.biomedcentral.com/submit 